\title{
The Single Crystal Spectrum of Hexakis(imidazole)nickel(II)Nitrate
}

\author{
Curt W. Reimann
}

Institute for Materials Research, National Bureau of Standards, Washington, D.C. 20234

(July 16, 1968)

\begin{abstract}
The crystal spectrum of hexakis(imidazole)nickel(II)nitrate from $7000 \mathrm{~cm}^{-1}$ to $30,000 \mathrm{~cm}^{-1}$ at liquid nitrogen temperature has been measured. Three spin-allowed and three spin-forbidden bands in this spectrum were assigned on the basis of octahedral ligand field symmetry. These assignments are compared with those made in several related materials. Important differences and similarities in spectral detail and their bearing on assignments in other strong field nickel(II) complexes, are discussed.
\end{abstract}

Key Words: Crystal spectrum; hexakis(imidazole)nickel(II)nitrate; octahedral nickel(II); spinforbidden bands.

\section{Introduction}

The visible spectra of nickel(II) complexes are characterized by spin-allowed and by relatively weaker spin-forbidden bands. In octahedral ligand fields three spin-allowed bands may be observed from which estimates can be made of the ligand field strength parameter, $D q$, and of the interelectronic repulsion parameter, $B$. These parameters can then be utilized to estimate the energies of all octahedral ligand field states which arise from the terms of the free nickel(II) ion. One difficulty with nickel(II) spectra which has led to conflicting assignments arises from the proximity of the ${ }^{1} \mathrm{E}_{g}(\mathrm{D})$ and ${ }^{3} \mathrm{~T}_{2} g(\mathrm{~F})$ energy levels. Transitions from the ${ }^{3} \mathrm{~A}_{2} g(\mathrm{~F})$ ground state to the ${ }^{1} \mathrm{E}_{g}(\mathrm{D})$ and ${ }^{3} \mathrm{~T}_{2} g(\mathbf{F})$ levels often result in two overlapping bands. As the value of $D q$ is derived from the energy of the ${ }^{3} \mathrm{~A}_{2} g(\mathbf{F}) \rightarrow{ }^{3} \mathrm{~T}_{2} g(\mathbf{F})$ transition, the proper assignment is required for a consistent interpretation. In a recent study Robinson, Curry and Busch $[1]^{1}$ measured solution spectra of some strong field nickel(II) complexes $\left(D q \sim 1000-1300 \mathrm{~cm}^{-1}\right)$. The spectral region from $10000-14000 \mathrm{~cm}^{-1}$ showed that the ${ }^{3} \mathrm{~A}_{2} g(\mathrm{~F}) \rightarrow$ ${ }^{1} \mathrm{E} g(\mathrm{D})$ transition "passes through" the ${ }^{3} \mathrm{~A}_{2} g(\mathbf{F}) \rightarrow$ ${ }^{3} \mathrm{~T}_{2} g(\mathrm{~F})$ transition from the high to the low energy side with increasing ligand field strength. This type

' Figures in brackets indicate the literature references at the end of this paper. of comparison of related spectra is an especially useful guide in the interpretation of spectra in which some bands are not observable or are obscured by stronger bands. Palmer and Piper [2], for example, assigned the energy levels in $\mathrm{Ni}\left(\right.$ bipyridine) ${ }_{3}^{+}$with the aid of the analysis reported by Robinson, Curry and Busch [1].

Although many solution spectra of nickel(II) in strong octahedral ligand fields have been reported, relatively few single crystal studies have been carried out. The principal advantages of the single crystal studies are derived from the fact that the spectra of species of known structure can be investigated at reduced temperatures. The improved resolution at low temperature may reveal the presence of band splittings and of spin-forbidden bands. Neither of these features may be evident in the solution spectra but both are of great importance in analyses which attempt to relate intensity distribution with molecular symmetry.

As part of a program in the investigation of the structural and spectroscopic properties of coordination compounds of transition metal ions single crystals were grown of hexakis(imidazole)nickel(II)nitrate, $\left(\mathrm{C}_{3} \mathrm{H}_{4} \mathrm{~N}_{2}\right)_{6} \mathrm{Ni}\left(\mathrm{NO}_{3}\right)_{2}$. A preliminary spectrum from $7000 \mathrm{~cm}^{-1}-31000 \mathrm{~cm}^{-1}$ was found to be free from the charge transfer or ligand absorption bands which frequently mask the much less intense $d-d$ bands. The x-ray structure determination of $\left(\mathrm{C}_{3} \mathrm{H}_{4} \mathrm{~N}_{2}\right)_{6} \mathrm{Ni}\left(\mathrm{NO}_{3}\right)_{2}$ 
has recently been completed and the coordination polyhedron has been shown to be a very slightly distorted octahedron [3]. In this paper the room temperature and liquid nitrogen temperature spectra of $\left(\mathrm{C}_{3} \mathrm{H}_{4} \mathrm{~N}_{2}\right)_{6} \mathrm{Ni}\left(\mathrm{NO}_{3}\right)_{2}$ are reported and an assignment is made of three spin-forbidden and three spin-allowed bands observed in these spectra. Finally, the spectral data for $\left(\mathrm{C}_{3} \mathrm{H}_{4} \mathrm{~N}_{2}\right)_{6} \mathrm{Ni}\left(\mathrm{NO}_{3}\right)_{2}$ as well as those for several related complexes are considered with regard to their bearing on assignments in general cases.

\section{Experimental Procedure}

Crystals of $\left(\mathrm{C}_{3} \mathrm{H}_{4} \mathrm{~N}_{2}\right)_{6} \mathrm{Ni}\left(\mathrm{NO}_{3}\right)_{2}$ were grown from stoichiometric aqueous solutions of $\mathrm{Ni}\left(\mathrm{NO}_{3}\right)_{2}$ and imidazole. Preliminary x-ray studies showed that these crystals are trigonal, space group R3. The crystal data based upon hexagonal indexing is as follows: $a=b=12.353 \pm 0.001 \AA, \mathrm{C}=14.803 \pm 0.002 \AA$ (where the error limits indicate standard deviations), of the individual measurements, to reflect their spread; or standard errors of preceding numbers to show how freely they are determined; $\rho_{0}=1.51 \mathrm{~g} \mathrm{~cm}^{-3}, p_{c}=1.505$ $\mathrm{g} \mathrm{cm}^{-3}, z=3$. The complete $\mathrm{x}$-ray structure determination showed that the complex cation consists of the nickel ion and six imidazole rings coordinated through the pyridine type $(>\mathrm{N})$ nitrogen atom. The nickel ion lies on a three-fold axis and a center of symmetry ( $\overline{3}$ site symmetry) and is, therefore, equidistant $(2.13 \AA)$ from six nitrogen atoms. The six nitrogen atoms describe a slightly distorted octahedron. The actual configuration of the coordinating nitrogen atoms may be described as resulting from a $0.04 \AA$ compression along one of the three-fold axes of a regular octahedron.

Spectroscopic measurements were performed on a recording spectrophotometer (Cary 14). Low temperature measurements were carried out in a cold finger type silica Dewar with liquid nitrogen as coolant.

The single crystal spectrum of $\left(\mathrm{C}_{3} \mathrm{H}_{4} \mathrm{~N}_{2}\right)_{6} \mathrm{Ni}\left(\mathrm{NO}_{3}\right)_{2}$ at room temperature and at liquid nitrogen temperature is shown in figure 1 . The spectrum consists of three symmetrical bands which occur at $11,100 \mathrm{~cm}^{-1}$, $18,150 \mathrm{~cm}^{-1}$, and at $28,700 \mathrm{~cm}^{-1}$ at liquid nitrogen temperature. A weak shoulder is observed near $13,300 \mathrm{~cm}^{-1}$ and a broad weak band occurs near $24,000 \mathrm{~cm}^{-1}$. A very weak and narrower band appears at $22,500 \mathrm{~cm}^{-1}$.

\section{Assignment of Spectrum}

The nickel(II) ion has eight $3 d$ electrons which permits the free ion terms ${ }^{3} \mathrm{~F},{ }^{3} \mathrm{P},{ }^{1} \mathrm{D},{ }^{1} \mathrm{G}$, and ${ }^{1} \mathrm{~S}$. In crystalline fields of octahedral symmetry the sevenfold degeneracy of the ${ }^{3} \mathrm{~F}$ free ion ground term is partially removed and the ${ }^{3} \mathrm{~A}_{2} g(\mathbf{F}),{ }^{3} \mathrm{~T}_{2} g(\mathbf{F})$, and ${ }^{3} \mathrm{~T}_{1} g(\mathrm{~F})$ crystal field states arise. The ${ }^{3} \mathrm{P}$ free ion term remains unsplit in an octahedral field $\left({ }^{3} \mathrm{~T}_{1} g(\mathrm{P})\right)$. The remaining free ion terms, ${ }^{1} \mathrm{D},{ }^{1} \mathrm{G}$, and ${ }^{\mathrm{S}} \mathrm{S}$ become the crystal field states ${ }^{1} \mathrm{E} g(\mathrm{D}),{ }^{1} \mathrm{~T}_{2} g(\mathrm{D}),{ }^{1} \mathrm{~A}_{1} g(\mathrm{G})+{ }^{1} \mathrm{~T}_{1} g(\mathrm{G})$ $+{ }^{1} \mathrm{E} g(\mathrm{G})+{ }^{1} \mathrm{~T}_{2} g(\mathrm{G})$ and ${ }^{1} \mathrm{~A}_{1} g(\mathrm{~S})$ respectively.

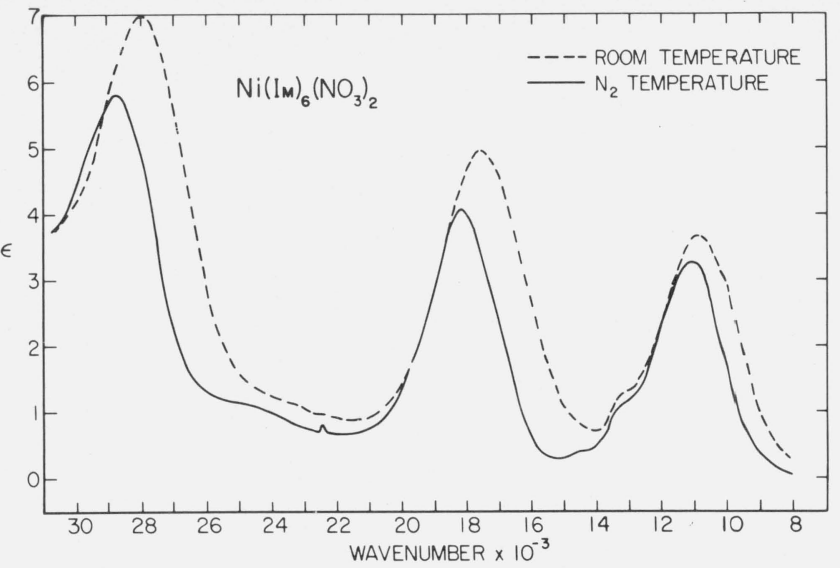

FIGURE 1. The single crystal spectrum of $\left(\mathrm{C}_{3} \mathrm{H}_{4} \mathrm{~N}_{2}\right)_{6} \mathrm{Ni}\left(\mathrm{NO}_{3}\right)_{2}$ at room temperature and at liquid nitrogen temperature.

The three broad bands observed in $\left(\mathrm{C}_{3} \mathrm{H}_{4} \mathrm{~N}_{2}\right)_{6} \mathrm{Ni}\left(\mathrm{NO}_{3}\right)_{2}$ at $11,100 \mathrm{~cm}^{-1}, 18,150 \mathrm{~cm}^{-1}$, and $28,700 \mathrm{~cm}^{-1}$ are readily identified with the three spin-allowed transitions. The $11,100 \mathrm{~cm}^{-1}$ band corresponds to a ${ }^{3} \mathrm{~A}_{2} g(\mathrm{~F}) \rightarrow{ }^{3} \mathrm{~T}, g(\mathrm{~F})$ transition while the $18,150 \mathrm{~cm}^{-1}$ and $28,700 \mathrm{~cm}^{-1}$ bands are assigned to the ${ }^{3} \mathbf{A}_{2} g(\mathbf{F})$ $\rightarrow{ }^{3} \mathrm{~T}_{1} g(\mathrm{~F})$ and ${ }^{3} \mathrm{~A}_{2} g(\mathbf{F}) \rightarrow{ }^{3} \mathrm{~T}_{1} g(\mathrm{P})$ transitions. The separation between the ${ }^{3} \mathrm{~A}_{2} g(\mathrm{~F})$ and ${ }^{3} \mathrm{~T}_{2} g(\mathrm{~F})$ states is equal to $10 D q$ where $D q$ is the parameter which is a measure of the ligand field strength. Thus, $D q$ for $\left(\mathrm{C}_{3} \mathrm{H}_{4} \mathrm{~N}_{2}\right)_{6} \mathrm{Ni}\left(\mathrm{NO}_{3}\right)_{2}$ is $1110 \mathrm{~cm}^{-1}$. The interelectronic repulsion parameter, $B$, can be computed from the energies of the ${ }^{3} \mathrm{~A}_{2} g(\mathbf{F}) \rightarrow{ }^{3} \mathrm{~T}_{1} g(\mathrm{~F})$ and ${ }^{3} \mathrm{~A}_{2} g(\mathrm{~F}) \rightarrow{ }^{3} \mathrm{~T}_{1} g(\mathrm{P})$ transitions and from the value of $D q$ [4]. The computed value of $B, 745 \mathrm{~cm}^{-1}$, represents a reduction from the free ion value by about $25 \%$. The Liehr-Ballhausen energy level diagram for the $3 d^{8}$ system [5] can now be used to aid in the assignment of the three observed spin-forbidden bands. The low intensity shoulder near $13,400 \mathrm{~cm}^{-1}$ is assigned to the ${ }^{3} \mathrm{~A}_{2} g(\mathrm{~F}) \rightarrow{ }^{1} \mathrm{E} g(\mathrm{D})$ transition. A relatively sharp weak band at $\sim 22,500$ $\mathrm{cm}^{-1}$ is assigned to the ${ }^{3} \mathrm{~A}_{2} g(\mathrm{~F}) \rightarrow{ }^{1} \mathrm{~A}_{1} g(\mathrm{G})$ transition and a much broader weak band observed at $\sim 24,000$ $\mathrm{cm}^{-1}$ is assigned to the ${ }^{3} \mathrm{~A}_{2} g(\mathrm{~F}) \rightarrow{ }^{1} \mathrm{~T}_{2} g(\mathrm{D})$ transition. The last two assignments are supported by the breadth of the bands as well as by their energies. The breadths differ as a consequence of the fact that the upper states have different dependencies upon $D q$. Thus, the ${ }^{1} \mathrm{~A}_{1} g(\mathrm{G})$ level, being less sensitive to changes in $D q$, is considerably less vibrationally broadened. The remaining possible spin-forbidden band in the spectral region studied, ${ }^{3} \mathrm{~A}_{2} g(\mathrm{~F}) \rightarrow{ }^{1} \mathrm{~T}_{1} g(\mathrm{G})$, is expected to lie just below the more intense and broader ${ }^{3} \mathrm{~A}_{2} g(\mathrm{~F})$ $\rightarrow{ }^{1} \mathrm{~T}_{1} g(\mathrm{P})$ band. It was not observed. A summary of the assignments for $\left(\mathrm{C}_{3} \mathrm{H}_{4} \mathrm{~N}_{2}\right)_{6} \mathrm{Ni}\left(\mathrm{NO}_{3}\right)_{2}$ is given in table 1 .

\section{Discussion}

The assignment of energy levels from $7000 \mathrm{~cm}^{-1}$ to $30,000 \mathrm{~cm}^{-1}$ in the spectrum of $\left(\mathrm{C}_{3} \mathrm{H}_{4} \mathrm{~N}_{2}\right)_{6} \mathrm{Ni}\left(\mathrm{NO}_{3}\right)_{2}$ 
TABLE 1. Transition energies and assignments of observed bands

\begin{tabular}{|c|c|}
\hline $\begin{array}{l}11,100 \mathrm{~cm}^{-1} \\
13,400 \\
18,150 \\
22,500 \\
24,000 \\
28,700\end{array}$ & $\begin{aligned}{ }^{3} \mathrm{~A}_{2} g(\mathrm{~F}) & \rightarrow{ }^{3} \mathrm{~T}_{2} g(\mathrm{~F}) \\
& \rightarrow{ }^{1} \mathrm{E} g(\mathrm{D}) \\
& \rightarrow{ }^{3} \mathrm{~T}_{1} g(\mathrm{~F}) \\
& \rightarrow{ }^{1} \mathrm{~A}_{1} g(\mathrm{G}) \\
& \rightarrow{ }^{1} \mathrm{~T}_{2} g(\mathrm{D}) \\
& \rightarrow{ }^{3} \mathrm{~T}_{1} g(\mathrm{P})\end{aligned}$ \\
\hline
\end{tabular}

allows a comparison with the results of several recent studies of nickel(II) complexes. In this analysis significant differences and similarities in assignments, intensities and transition energies between $\left(\mathrm{C}_{3} \mathrm{H}_{4} \mathrm{~N}_{2}\right)_{6}$ $\mathrm{Ni}\left(\mathrm{NO}_{3}\right)_{2}$ and each related spectrum will be discussed in terms of molecular symmetry. Finally the results of this analysis will be summarized to aid in making assignments in general cases.

The single crystal spectrum of $\mathrm{Ni}\left(\mathrm{NH}_{3}\right)_{4}(\mathrm{NCS})_{2}$ reported by Hare and Ballhausen [6] offers a close comparison with the spectrum of $\left(\mathrm{C}_{3} \mathrm{H}_{4} \mathrm{~N}_{2}\right)_{6} \mathrm{Ni}\left(\mathrm{NO}_{3}\right)_{2}$ because NCS and $\mathrm{NH}_{3}$ occupy adjacent positions in the spectrochemical series and the ligand field at the nickel(II) ion in $\mathrm{Ni}\left(\mathrm{NH}_{3}\right)_{4}(\mathrm{NCS})_{2}$ is also very nearly octahedral. The similarity in structure between $\mathrm{Ni}\left(\mathrm{NH}_{3}\right)_{4}(\mathrm{NCS})_{2}$ and $\left(\mathrm{C}_{3} \mathrm{H}_{4} \mathrm{~N}_{2}\right)_{6} \mathrm{Ni}\left(\mathrm{NO}_{3}\right)_{2}$ is reflected in the similarity in their spectra. For example, the transition identified as ${ }^{3} \mathrm{~A}_{2} g(\mathbf{F}) \rightarrow{ }^{1} \mathrm{E} g(\mathrm{D})$ occurs in both spectra near $13,000 \mathrm{~cm}^{-1}$. More significantly, the intensity with which this transition occurs in both spectra compared with that of the adjacent ${ }^{3} \mathrm{~A}_{2} g(\mathrm{~F})$ $\rightarrow{ }^{3} \mathrm{~T}_{2} g(\mathrm{~F})$ transition is consistent with its assignment as a spin-forbidden band. In addition, the energies and relative intensities of the spin-allowed bands in these spectra are quite similar. The spectrum of $\mathrm{Ni}\left(\mathrm{NH}_{3}\right)_{4}\left(\mathrm{NO}_{2}\right)_{2}$ reported by Hare and Ballhausen [6], on the other hand, differs markedly from those compared above. In the $11-14,000 \mathrm{~cm}^{-1}$ region, the spectrum of $\mathrm{Ni}\left(\mathrm{NH}_{3}\right)_{4}\left(\mathrm{NO}_{2}\right)_{2}$ (in both polarization directions) has a broad band with a shorter wavelength shoulder of comparable intensity. The band corresponding to the ${ }^{3} \mathrm{~A}_{2} g(\mathrm{~F}) \rightarrow{ }^{3} \mathrm{~T}_{1} g(\mathrm{~F})$ transition occurs about $2000 \mathrm{~cm}^{-1}$ higher and with greater relative intensity than the corresponding transitions in $\mathrm{Ni}\left(\mathrm{NH}_{3}\right)_{4}(\mathrm{NCS})_{2}$ and $\left(\mathrm{C}_{3} \mathrm{H}_{4} \mathrm{~N}_{2}\right)_{6} \mathrm{Ni}\left(\mathrm{NO}_{3}\right)_{2}$ and the band corresponding to the ${ }^{3} \mathrm{~A}_{2} g(\mathrm{~F}) \rightarrow{ }^{3} \mathrm{~T}_{1} g(\mathrm{P})$ transition in $\mathrm{Ni}\left(\mathrm{NH}_{3}\right)_{4}\left(\mathrm{NO}_{2}\right)_{2}$ was too intense to be observed.

Robinson, Curry, and Busch [1] recorded the spectra of a series of nickel-strong field ligand complexes to determine the relative behavior of the neighboring ${ }^{3} \mathrm{~A}_{2} g(\mathrm{~F}) \rightarrow{ }^{1} \mathrm{E} g(\mathrm{D})$ and ${ }^{3} \mathrm{~A}_{2} g(\mathrm{~F}) \rightarrow{ }^{3} \mathrm{~T}_{2} g(\mathrm{~F})$ transitions as a function of ligand field strength. In each spectrum one band of an overlapping pair of bands was assigned to the ${ }^{3} \mathrm{~A}_{2} g(\mathrm{~F}) \rightarrow{ }^{1} \mathrm{E} g(\mathrm{D})$ transition and the other to the ${ }^{3} \mathrm{~A}_{2} g(\mathrm{~F}) \rightarrow{ }^{3} \mathrm{~T}_{2} g(\mathrm{~F})$ transition. An analysis of these assignments indicated that for small $D q$ the ${ }^{1} \mathrm{E} g(\mathrm{D})$ level lies above the ${ }^{3} \mathrm{~T}_{2} g(\mathrm{~F})$ while for large $D q$ the reverse obtains. From this analysis a band crossover point at $D q \sim 1200 \mathrm{~cm}^{-1}$ was estimated. In all spectra utilized in the Robinson et al. [1] analysis the overlapping bands have comparable intensity. In the spectrum of $\mathrm{Ni}\left(\mathrm{NH}_{3}\right)_{4}(\mathrm{NCS})_{2}$ and of $\left(\mathrm{C}_{3} \mathrm{H}_{4} \mathrm{~N}_{2}\right)_{6} \mathrm{Ni}\left(\mathrm{NO}_{3}\right)_{2}$, however, the ${ }^{3} \mathrm{~A}_{2} g(\mathrm{~F}) \rightarrow{ }^{1} \mathrm{Eg}(\mathrm{D})$ transition not only ap- peared with a very small fraction of the intensity of the ${ }^{3} \mathrm{~A}_{2} g(\mathrm{~F}) \rightarrow{ }^{3} \mathrm{~T}_{2} g(\mathrm{~F})$ transition but also at $\sim 1200 \mathrm{~cm}^{-1}$ higher energy than in the most closely comparable solution spectra used in the Robinson et al. [1] analysis. Thus, the single crystal studies would seem to indicate that a band crossover occurs significantly above $D q=1200 \mathrm{~cm}^{-1}$.

Palmer and Piper [2] investigated the single crystal spectra of $\mathrm{Ni}$ (bipyridine $)_{3}{ }^{++}$which they interpreted on the basis of trigonal symmetry. A sharp band near $21,000 \mathrm{~cm}^{-1}$ was assigned as the ${ }^{3} \mathrm{~A}_{2} g(\mathrm{~F}) \rightarrow{ }^{1} \mathrm{~A}_{1} g(\mathrm{G})$ transition which occurs at $\sim 22,500 \mathrm{~cm}^{-1}$ in $\left(\mathrm{C}_{3} \mathrm{H}_{4} \mathrm{~N}_{2}\right)_{6} \mathrm{Ni}\left(\mathrm{NO}_{3}\right)_{2}$. A shoulder which was observed near $23,000 \mathrm{~cm}^{-1}$ in $\mathrm{Ni}$ (bipyridine $)_{3}{ }^{++}$was assigned by Palmer and Piper as a ligand transition because of its estimated small breadth. However, the occurrence of a weak band near $24,000 \mathrm{~cm}^{-1}$ in $\left(\mathrm{C}_{3} \mathrm{H}_{4} \mathrm{~N}_{2}\right)_{6} \mathrm{Ni}\left(\mathrm{NO}_{3}\right)_{2}$ suggests that the $23,000 \mathrm{~cm}^{-1}$ band in $\mathrm{Ni}$ (bipyridine $)_{3}{ }^{++}$ may be ascribed to a $d-d$ transition $\left({ }^{3} \mathrm{~A}_{2} g(\mathrm{~F}) \rightarrow{ }^{1} \mathrm{~T}_{2} g(\mathrm{D})\right)$. The two bands near $12,000 \mathrm{~cm}^{-1}$ in $\mathrm{Ni}$ (bipyridine) ${ }_{3}{ }^{++}$ were assigned by comparison with the spectral data reported by Robinson et al. [1]. The lower energy band was assigned as the ${ }^{3} \mathrm{~A}_{2} g(\mathrm{~F}) \rightarrow{ }^{1} \mathrm{Eg}(\mathrm{D})$ transition.

A summary of the assignments made in the aforementioned spectra shows that the intensity of the band assigned to the spin-forbidden ${ }^{3} \mathrm{~A}_{2} g(\mathrm{~F}) \rightarrow{ }^{1} \mathrm{E} g(\mathrm{D})$ transition varies over a wide range with respect to that of the spin-allowed ${ }^{3} \mathrm{~A}_{2} g(\mathrm{~F}) \rightarrow{ }^{3} \mathrm{~T}_{2} g(\mathrm{~F})$ transition. In the general case, then, when these adjacent bands appear with comparable intensity, an assignment cannot be made on the basis of intensity alone. Nor are these transitions necessarily distinguishable by their relative energies as this has been shown to depend upon $D q$. These observations illustrate how the problem of assignments in the region from 10 to $14,000 \mathrm{~cm}^{-1}$ is bound up with the problem of intensity distribution. Of the spectra recorded in the studies cited, only $\left(\mathrm{C}_{3} \mathrm{H}_{4} \mathrm{~N}_{2}\right)_{6} \mathrm{Ni}\left(\mathrm{NO}_{3}\right)_{2}$ and $\mathrm{Ni}\left(\mathrm{NH}_{3}\right)_{4}(\mathrm{NCS})_{2}$ are in conformity with the octahedral model and, as indicated above, they have similar intensity distributions. The single crystal spectrum of $\mathrm{Ni}\left(\mathrm{NH}_{3}\right)_{4}\left(\mathrm{NO}_{2}\right)_{2}$ differs in essential detail from these but has been intrepreted successfully on the basis of tetragonal symmetry. The remaining spectra, when considered together, indicate that the ${ }^{1} \mathrm{Eg}(\mathrm{D})$ level lies below ${ }^{3} \mathrm{~T}_{2} g(\mathrm{~F})$ for $D q>1200$. As already noted, however, in the spectra in which the intensity of the ${ }^{3} \mathrm{~A}_{2} g(\mathrm{~F})$ $\rightarrow{ }^{1} \mathrm{Eg}(\mathrm{D})$ transition is consistent with its assignment as a spin-forbidden band, it occurs $\sim 1200 \mathrm{~cm}^{-1}$ higher than in spectra for which a relatively high intensity ${ }^{3} \mathrm{~A}_{2} g(\mathrm{~F}) \rightarrow{ }^{1} \mathrm{E} g(\mathrm{D})$ transition has been assigned. These wide variations in spectral characteristics of apparently structurually related compounds are difficult to ascribe to variations in singlet-triplet mixing alone. Rather it appears that another factor, the presence of lower symmetry components in the ligand field of the metal ion, is of greater significance. The importance of ligand field components with lower than octahedral symmetry lies in the fact that these components must split the ${ }^{3} \mathrm{~T}$ octahedral states and thereby redistribute the intensity associated with spin-allowed transitions. If the departure from octahedral symmetry is not 
large, additional energy levels will appear in the 10 to $14,000 \mathrm{~cm}^{-1}$ region. If such levels are identified exclusively with ${ }^{3} \mathrm{~A}_{2} g(\mathrm{~F}) \rightarrow{ }^{3} \mathrm{~T}_{2} g(\mathrm{~F})$ transitions, a consistent account in terms of the ligand field theory cannot be given. In such cases the detailed crystal structure must be determined so that an interpretation can be made in terms of the detailed molecular symmetry.

\section{References}

[1] Robinson, M. A., Curry, J. D., and Busch, D. H., Inorg. Chem. 2, 1178 (1963).

[2] Palmer, R. A., and Piper, T. S., Inorg. Chem. 5, 864 (1966).

[3] Santoro, A., Mighell, A. D., Zocchi, M., and Reimann, C. W., Acta. Cryst., in press.

[4] Bostrup, O., Jorgensen, C. K., Acta. Chem. Scand. 11, 1223 (1957).

[5] Liehr, A. D., and Ballhausen, C. J., Ann. Phys. (N.Y.), 6, 134 (1959).

[6] Hare, C. R., and Ballhausen, C. J., J. Chem. Phys. 40, 792 (1964).

(Paper 72A6-525) 